\title{
Conocer la Catedrall de Sal es una mina de cultura colombiana
}

Quien visite a Zipaquirá recibe el

Rosa

Spada

beneficio de favores ciertos e insustituibles: encanto para los ojos, aire purísimo para los pulmones y el regocijo y la paz para el espíritu en la contemplación del Santuario subterráneo de Guazá.

\section{INTRODUCCIÓN}

Los profesores de español, de arte, de literatura y de historia para extranjeros en la ciudad de Bogotá, Colombia organizan dos veces al mes visitas a lugaresturísticos que forman parte del patrimonio cultural de ese país. Ejemplo de ell o fue la visita a la catedral de Sal en Zi paquirá. Tan sólo a 50 kilómetros al norte de la capital de Colombia, a unos 45 minutos (por auto) y casi dos horas por tren, se local iza el municipio de Zipaquirá, a una al tura de 2750 metros en la Cordillera Oriental de los Andes. En ese lugar se encuentra el Cerro del Zipa, que forma parte de las minas de sal dentro de las cual es se construyó la Catedral, una magnífica obra de arte e ingeniería, bajo la tierra, en las salinas.

La Catedral está dedicada a la Virgen del Rosario, que los indígenas Ilamaban: "Nuestra Señora de Guasá". En sus socavones se concibieron espacios para las 14 estaciones del Vía Crucis, una bellísima cruz de grandes proporciones tallada en bajorrelieve, cuyailuminación produce una apacible ilusión óptica, capillas y estancias sacramentales en un ambiente de sombras y penumbra que nos transmiten paz y armonía sublimes. 


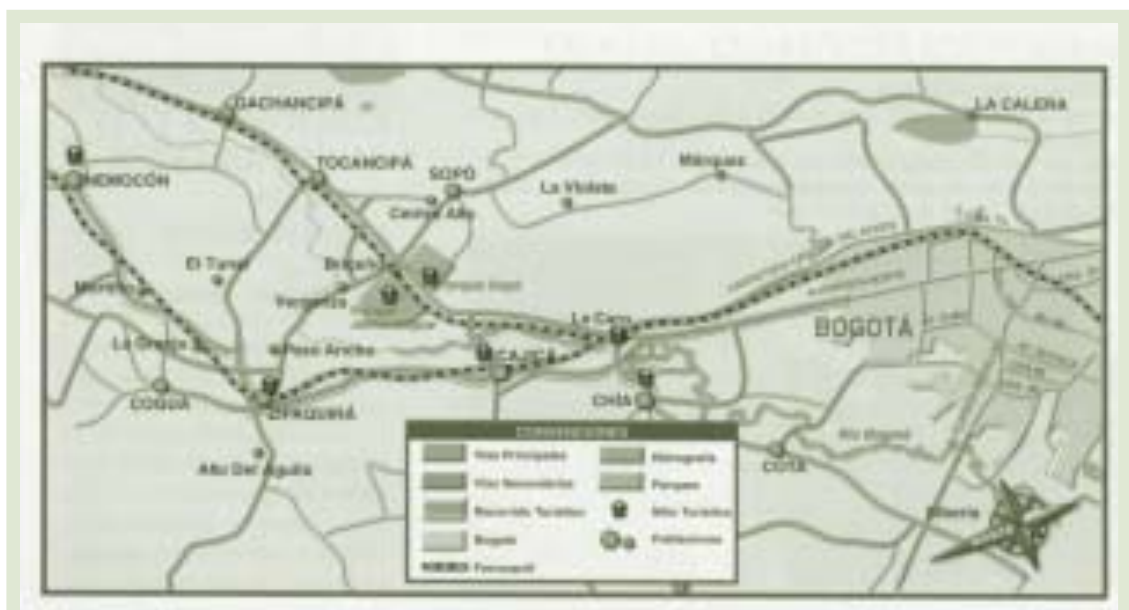

Zipaquirá es un lugar sagrado de sal. Su nombre deriva de la pal abra en lengua indígena chicaquicha que significa al "pie del suegro o yerno" y de la palabra chipaquicha al "pie de nuestro padre"; Zipaquirá, —que hasta antes del siglo pasado se escribía Cipaquirá- significa "Ciudad o poblado de nuestro Padre", era el sitio donde habitaban los indígenas muiscas a los pies del Cerro de Zipa.

Las salinas de Zipaquirá tienen una existencia milenaria y fueron expl otadas por los muiscas, que además del uso práctico, hicieron de la sal su principal instrumento de intercambio, equivalía a su moneda. Por ese motivo, la sal, fue causa de varios conflictos entre los muiscas quienes trataban de ejercer dominio absoluto sobre ese preciado bien.

\section{LA LEYENDA}

Según la leyenda indígena, la sal fue descubierta por un niño muisca, que jugando con sus amigos en los al rededores de las minas, tuvo un tropiezo y al caer su boca gol peó con un trozo de piedra, de un sabor extraño. El niño llevó la roca a sus mayores, que descubrieron en él un condimento ideal para sus alimentos y un medicamento muy efectivo para al gunas enfermedades. LoS indígenas pronto aprendieron a transformar a la sal de roca llamada chigua en sal del consumo. 
En 1538 los españoles encontraron a varios indígenas que trabajaban la tierra cultivando papa, maíz y calabaza, al lado del cerro de Pueblo Viejo. Y su mayor riqueza era la explotación de las minas de sal en Zipaquirá, Nemocón y Teusa, la sal brotaba de la tierra a través de varias fuentes de agua. Los muiscas col ocaban en juiches ${ }^{1}$ la chigua o sal en piedra negra a cocer a fuego hasta que la sal muera secara; una vez compactada y convertida en "panes de sal" la comercial izaban con otras poblaciones por productos como mantas, frutos, oro y esmeral das. Tan es así que los español es se encontraron con un comercio total mente establecido por toda la región; es a partir deese momento que comienza el adoctrinamiento de los grupos indígenas por losfrailesfranciscanosy posteriormente por la orden de los dominicos, quienes con mucho trabajo lograron imponer entre los muiscas una nueva religión que cambió, en parte, sus costumbres y sus tradiciones.

Entre los varios cambios efectuados por los españoles estuvo el traslado de los indígenas habitantes de gran parte de esta vasta sabana, al Pueblo Viejo, a Pasoancho, Portachuel o y Pacaquem (donde actual mente se encuentra la ciudad de Zi paquirá) y a las tierras destinadas únicamente para cultivos. En Pacaquem, se ordenó organizar las calles, trazar la plaza y erigir una iglesia, es así como se funda Zi paquirá, más o menos alrededor del año 1600.

Zipaquirá a través de todos estos años, ha sufrido varias transformaciones. Pasó de ser pueblo a un corregimiento; más tarde a parroquia y posteriormente fue ascendida a municipio. En 1871 se convirtió en el centro político del Virreinato, asimismo, fue punto clave en la Revolución de los Comuneros, hasta culminar el 20 de julio de 1810 en el Grito de Independencia, en ese momento se le otorga la calidad de Villa de Zipaquirá. 
2 Café negro, lo que en otras partes se conoce como café americano.

3 Café con leche.

4 Pan horneado relleno de queso.

5 Dulce de leche, muy parecido a la cajeta mexicana. De ese mismo color y textura.

6 Grupo de músicos que tocan: la guitarra, el guiro, el violín y cantan canciones populares. Entre ellos los famosos vallenatos, que siempre tienen estribillo.

\section{PRIMERAS IMPRESIONES}

Nuestro recorrido comienza en la ciudad de Bogotá, nos reunimos en el famoso café J uan Valdez, en el cual los estudiantes y los profesores comparten el delicioso café, y para empezar a familiarizarnos con los términos pedimos un tinto ${ }^{2}$ y después otros más se animaron a tomarse un perico ${ }^{3}$ acompañado con al mojábanas, ${ }^{4}$ pan con arequipe, ${ }^{5}$ entre otras delicias. Posteriormente partimos para tomar el tren turístico que recorrela región central delaSabana, uno de los paisajes más hermosos de Colombia. Primero llegamos a la población de Chía, Chía conserva su nombre en lengua chibcha término asociado al cul to de la Luna y a Bachué, diosa tutelar de la cultura precolombina de los muiscas. El siguiente destino es la población de Cajicá, antigua fortaleza militar de los muiscas. Sobre la vía se observan hermosas haciendas, como la de Hato Grande. A pocos kilómetros se vislumbra una panorámica del municipio de Zipaquirá, nombre que evoca a Zipa, máximo jerarca de los muiscas y quien dirigía di rectamente la explotación de las ricas minas de sal que desde tiempos inmemorial es han hecho famosa esta población. Asimismo, la vivencia en el tren es un encuentro de cultura popular, porque el trayecto es amenizado por el grupo de músicos que cantan y tocan varios instrumentos. Las "papayeras"6 amenizan el recorrido con canciones caribeñas. Algunos de los alumnos se animan a corear parte de los estribillos.

Posteriormente, - después de casi dos horas de recorrido, penetramos en la mina de sal-, Catedral de Sal, Ia idea de construir una catedral de Sal, surgió de los mismos indígenas quienes explotaban la mina, desde el siglo XV antes del descubrimiento de América, después de la conquista se realizó en un socavón un nicho labrado en roca para rendirle culto y devoción a la Virgen del Rosario de Guasá, patrona de los mineros. Su boca de entrada se abre en la cumbre de una colina y penetrar en su interior es desafiar las tinieblas y la oscuridad. Se comienza por un largo túnel parecido a un catafal co y al ir introduciéndonos es penetrar en el mundo de las sombras, que poco a poco abre un espacio de luz que permite ver las esculturas de ángeles en los muros y en las paredes hechas de 
sal, mientras continuamos avanzando la frial dad de las tinieblas nos sobrecoge, las galerías se entrecruzan y seguimos avanzando por los laberintos de las lágrimas de sal, acompañados por las imágenes sacras desde las profundidades eternas de la mina.

\section{DESCRIPCIÓN DEL INTERIOR DE LA CATEDRAL}

Después de recorrer un largo camino subterráneo sellega sorpresivamente a los umbrales de la basílica, portentosa y fantástica. La al tura máxima de este monumento de sal es de $22 \mathrm{~m}$. Tres arcos de roca levantados a $75 \mathrm{~m}$ del suelo, soportan las tensiones de tan enorme oquedad. La longitud del piso es de $120 \mathrm{~m}$ y la superficie del templo, excluyendo la que ocupan los pilares, es de $5500 \mathrm{~m}^{2}$; estos pilares tienen $22 \mathrm{~m}$ de altura y su espesor, es tan considerable que 20 personas apenas las pueden abrazar.

El templo tiene cuatro naves y en ellas se siguen las cuatro etapas de la vida de J esús. La nave de la izquierda Ilamada del "Nacimiento" simula un pesebre de estilo santafereño; sigue la nave del "Bautisterio" con una fuente simbólica del bautismo por inmersión. La central o de Redención lleva al fondo una inmensa cruz que proyecta la sombra augusta de Cristo sobre el techo de sal cristal izada. En la nave de la derecha están los pasos del "Vía Crucis" en números romanos, dorados y de gran tamaño, así como el Coro; y en el altar del fondo está colocada la imagen de la Virgen del Rosario de Guazá.

El estilo del templo tiene influencia románica de las colosales catacumbas, además es única en el mundo porque las excavaciones de los filones de sal han modelado formas bastante caprichosas, al gunas de las paredes conservan la huella de la piqueta que ha servido para extraer la sal. El altar principal está colocado de tal manera que permite celebrar la misa con el sacerdote de cara a los fieles. Monseñor Samoré al contemplar por primera vez este prodigio, exclamó:

El extranjero que visita a Colombia puede admirar muchas cosas: caudal osos ríos, selvas impenetrables, nevados eternos, minas de esmeral das, hermosas plantaciones de café; 
pero de todo esto más o menos tendría una idea, por haberlas conocido en otras partes, pero una inmensa montaña de sal, de más de 400000 m de extensión, y en las entrañas de esa montaña una catedral de Sal, seguramente ningún turista la ha visto, ni la ha imaginado.

La sal, para todo extranjero se saca del mar o de fuentes saladas, pero no de una montaña, revestida de verde vegetación por fuera y por dentro compuesta de sal compacta y petrificada que es preciso extraer con dinamita.

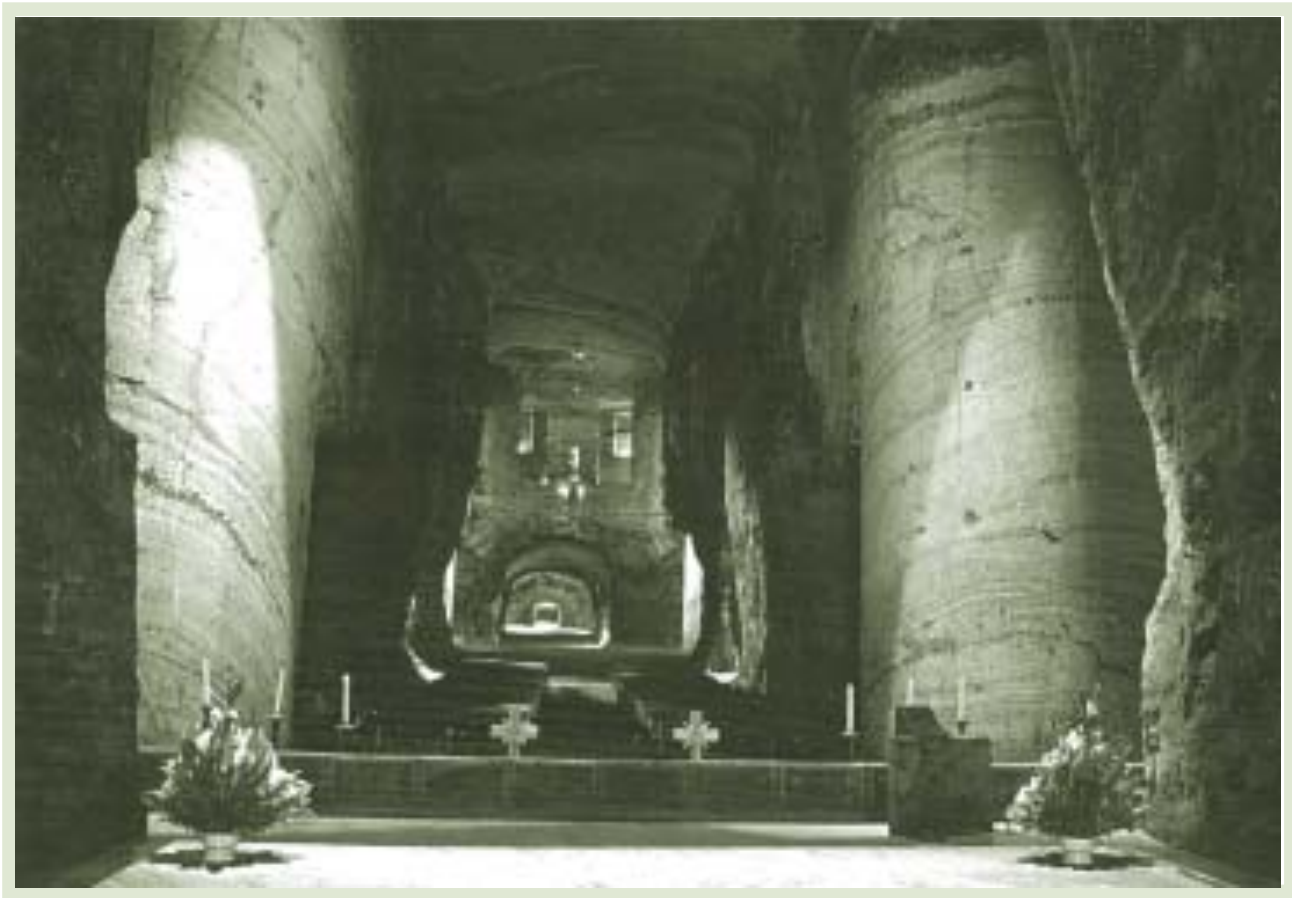

VIVENCIAS DESCRITAS POR LOS ALUMNOS

"En el interior de esa cueva sagrada todo está tallado de sal: cruces monumentales, ángeles y estatuas de vírgenes, todo de sal o roca salina. Antes de llegar a la nave principal de la catedral, se puede meditar en alguna de las 14 capillas que forman el Vía Crucis que nos Ileva por un laberinto de socavones. En la primera capilla, se marca el comienzo de la Pasión de Cristo, —casi nos asustamos de la austeridad con que fue diseñada-. Después en medio de las tinieblas de las cuevas se erige una gran cruz, sin ninguna decoración. Encima de la cruz, la bóve- 
da negra y desnuda. En este lugar en especial nos sentimos obligados a guardar silencio. Todos enmudecimos. Más adelante, nos quedamos sol os en la oscuridad, lentamente nos dirigi mos a contemplar las demás capillas. Todas son muy parecidas. En la mayoría de las capillas, la cruz está rodeada de una luz misteriosa, azulada, rojiza y plateada que nos provoca evocar soledad, meditación, dolor y esperanzas de eternidad. El silencio subterráneo y la atmósfera mística se nos pega a la piel. Acompañados por los ecos difusos de un canto lejano que nos llega desde la profundidad oscura de los otros socavones, nos acercamos a la Catedral misma, descendiendo cada vez más a las entrañas de la tierra. El túnel parece Ilevarnos cada vez más lejos del sol, al corazón de las tinieblas, donde sólo los cristales de sal brillan, cada vez que los toca suavemente un rayo de luz. Estamos en el reino místico de la noche oscura que nos rodea. Lejanamente nos envuelven un sinfín de voces, sonidos y ecos. De vez en cuando aparece un ángel en la pared del socavón. Más adelante por una escalera muy estrecha y oscura bajamos al centro de la catedral y nos topamos con una copia de la 'Creación de Adán' de Miguel Ángel, nos es una pintura como en la Capilla Sixtina, es un relieve de mármol de sal, de gran dimensión. Encima se encuentra una cúpula rocosa iluminada de luz azulada. Miremos donde miremos tanto de lejos como de cerca nos rodea la inmensa cruz tal lada en la roca del coro de la catedral, Ilena de luz, de luz espiritual, de luz que nos penetra el alma. Después de pasar tres horas bajo la tierra, en las estalactitas de lágrimas de sal, nuestros ojos están añorando el mundo de arriba, la luz solar. En el camino de regreso casi nos perdemos por seguir un túnel quellevaba de nuevo hacia abajo, hacia las profundidades de la mina que nos acoge y nos atrapa y nos hace recordar que sólo somos mortales en este reino de luz y sombras. Cuando nos acercamos a la puerta de la salida, el impacto de la luz en nuestras pupilas nos hace brotar lágrimas de sal, el choque de tanta claridad nos resulta asombroso. Todo nuestro cuerpo y nuestros sentidos necesitan al gunos minutos para acostumbrarse de nuevo a la luz del día.

Después de compartir y describir estas vivencias, los alumnos y profesores decidimos comer en los restauran- 
7 El famoso ajiaco es un caldo hecho con pechuga de pollo, varias clases de papa, que se sirve acompañado de crema y alcaparras.

8 El puchero santafereño, es un caldo elaborado con carne de res, papas, elotes.

9 Se trata de carnes asadas en las brasas. Mezcla de carne de res, pollo y cerdo.

10 Muy parecido a los tamales de nuestro país, pero en lugar de pasas lleva chocolate. También se les conoce con el nombre de "envueltos".

11 Es leche con cuajo, que queda en forma de flan, al que se le agrega miel de piloncillo.

12 En los estribillos del vallenato se comen palabras, por ejemplo en lugar de decir: destripar, solo dicen estripe. tes que ofrecen platos típicos. Incursionamos en el mundo de los sabores, los colores, los olores y las texturas. Probamos ajiaco, ${ }^{7}$ puchero santafereño, ${ }^{8}$ la picada de carnes, ${ }^{9}$ el tamal con chocolate ${ }^{10}$ y para endulzarnos el alma: Ia cuajada con melao, ${ }^{11}$ el postre de natas, las brevas con arequipe y por supuesto el exquisito café de Colombia. Aquí nuevamente los estudiantes realizan una breve descripción de lo que les parecela comida, si descubren sabores nuevos, también comparan estos platillos con sus respectivos platos típicos.

Y más tarde al caer la estrel las sobre nuestras cabezas, disfrutamos de la músicatípica, de los famosos vallenatos. Y al gunos nos animamos a corear este estribillo:

Adiós que te vaya bien

Que te aplaste un carro

Y te estripe ${ }^{12}$ el tren".

Esta vivencia, experiencia se convierte en una inmersión de cultura, de historia, de gastronomía y folclore y también porque no de luz espiritual. Una vivencia espectacular. 